\title{
SOFT TARgeTS - PossibILITIES OF THEIR IDENTIFICATION
}

\author{
Dora Lapkova, Lukas Kotek \& Lukas Kralik
}

\author{
Tomas Bata University in Zlín, Zlín, Czech Republic
}
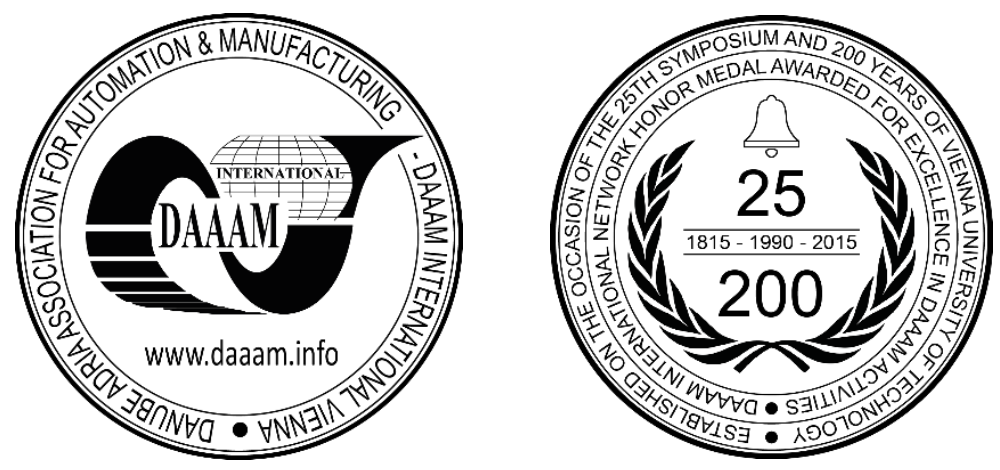

This Publication has to be referred as: Lapkova, D[ora]; Kotek, L[ukas] \& Kralik, L[ukas] (2018). Soft Targets Possibilities of Their Identification, Proceedings of the 29th DAAAM International Symposium, pp.0369-0377, B. Katalinic (Ed.), Published by DAAAM International, ISBN 978-3-902734-20-4, ISSN 1726-9679, Vienna, Austria DOI: $10.2507 / 29$ th.daaam.proceedings.053

\begin{abstract}
This article is focused on the Soft targets and especially on the possibilities of their identification. The terrorist attacks are one of the biggest security problems in the modern world. The armed forces try to solve this situation and to stop these attacks. However, the solving of this security problem is not only in the competence of the armed forces. The police and the army have many advantages, but it is impossible that these people will always be everywhere. The goal of this article is to present our method of identification of the Soft targets. In the following sections, we will write about the definition of the Soft targets, their characteristics and the statistics of the terrorist attacks in 2017. The main section is about our new method of the identification of the Soft targets. During our experiment, we used several mathematical methods of classification (Scoring method, Fuller's method, Saaty's method). The interesting section is about future research, because we present only initial study in this article and we have ambitions to create a classification of the Soft targets and to describe possibilities of their protection - with focus on behavior analysis and profiling.
\end{abstract}

Keywords: soft target; definition; identification; criteria; method

\section{Introduction}

Terrorism is a threat that exists for a very long time. In recent years, however, it has become a phenomenon due to the Islamic State and its attacks on the territory of western countries [1],[2],[3],[4],[5],[6]. Security experts are trying to grasp this dynamically developing problem and to find the solution. One of the problems is that modern science does not respond to this development, there are only inconsistent views on what is the target of terrorist attacks in Europe, how to identify and to categorize them.

Experts analyze specific attacks and search for a repeat pattern of attacker's behavior (called modus operandi). A satisfactory definition of the soft targets exists for two years [7]. Nevertheless, their identification and meaningful division into corresponding categories do not still exist. We strive to fill this gap in security studies with a methodological concept that will help for better understanding of this issue. The Islamic state has changed the modus operandi of terrorist attacks inspired by religion [8]. The differences are that the attacks are simple and the attackers use weapons that are more accessible (for example cars, trucks, knives, etc.). The other important point is that the attacker does not so often commit suicide. 


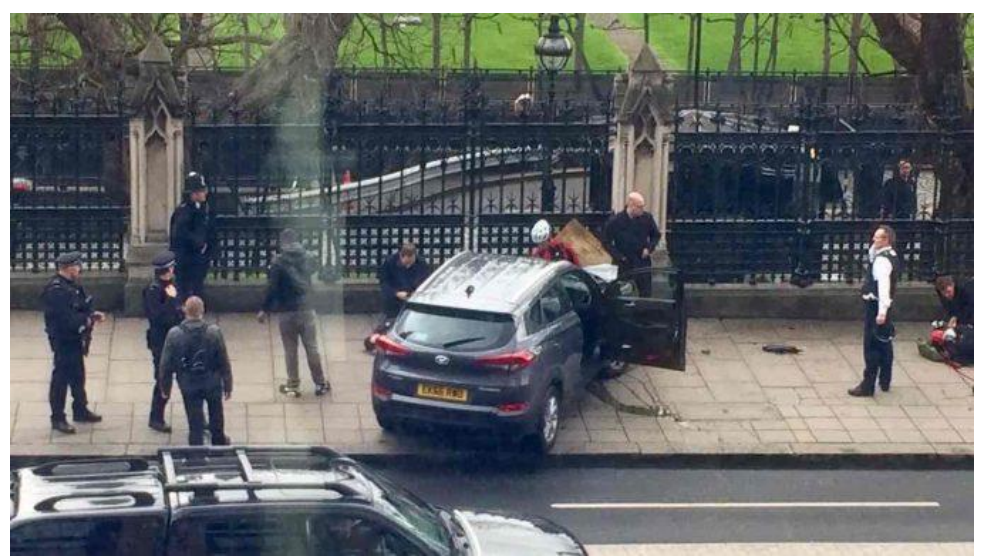

Fig. 1. Terrorist attack in London, 2017. [9]

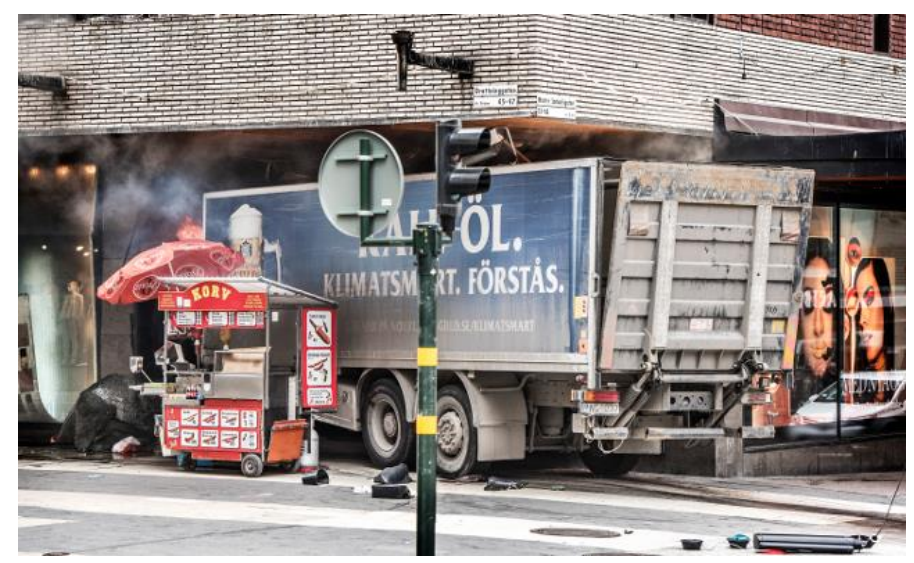

Fig. 2. Terrorist attack in Stockholm, 2017. [10]

\section{Statistics}

This section describes the terrorist attacks in Europe. The statistics are focused on the year of 2017. This year was a breakthrough in problematic of the Soft targets. In 2017, there was a rapid increase of terrorist attacks in Europe [8], as you can see in following graphs. In this section, we create several graphs focused on the development of the modus operandi. We also tried to find some trend in the target of attacks. It is important information for us because we can predict another attack - theoretically. We analyze much information with one goal - the prediction of next target. It is very complicated. In the following graphs (Fig. 3, 4, 5, 6), we have compiled the information about the terrorist attacks focusing on Europe and year of 2017.

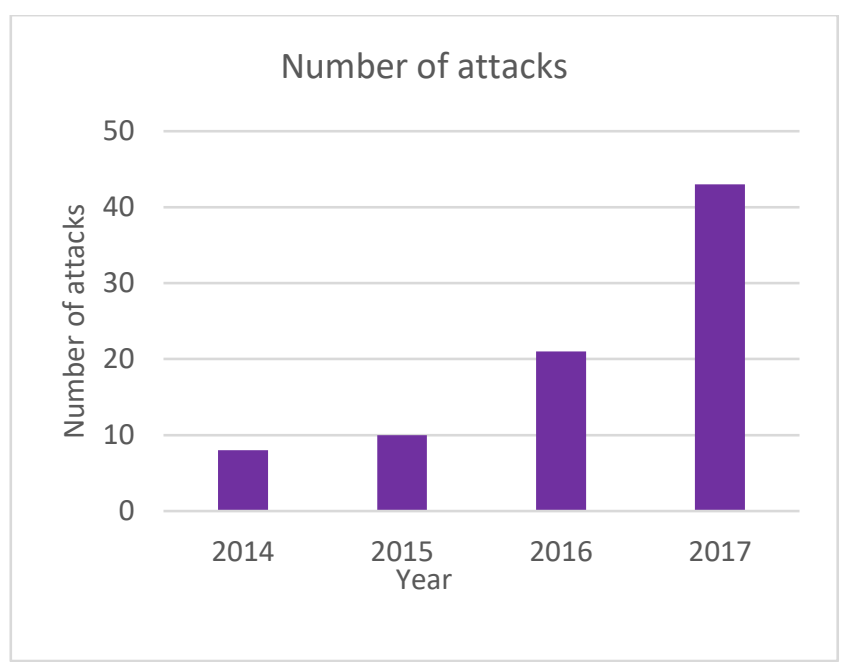

Fig. 3. Number of attacks in years $2014-2017$ [8] 
In Fig. 3, we compare a number of attacks in years from 2014 to 2017 in Europe. We can see that the attacks doubled in the year of 2017 compared to the year of 2016.

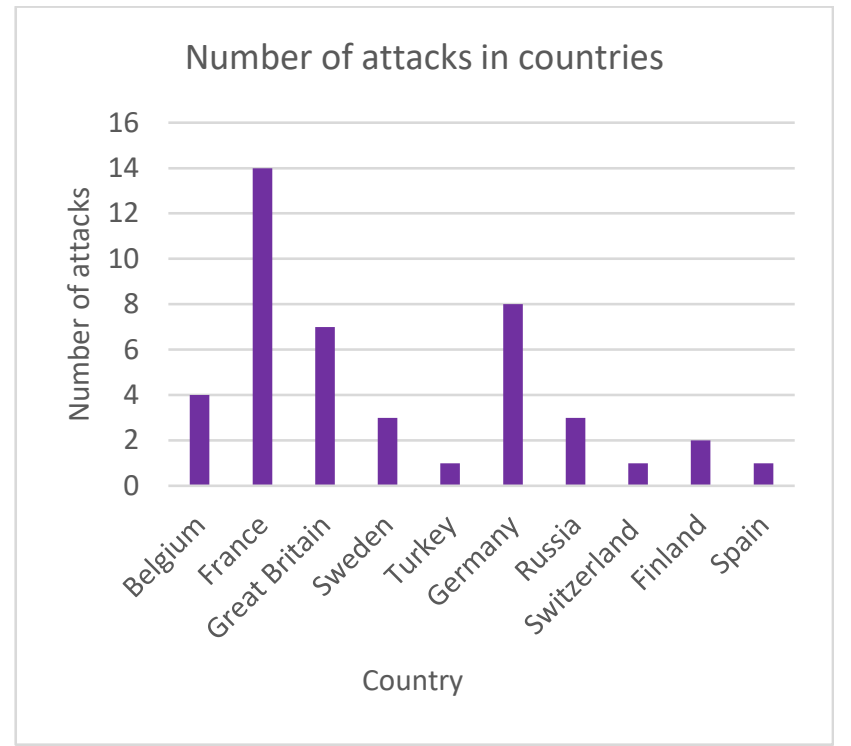

Fig. 4. Number of attacks in Europe in 2017 [8]

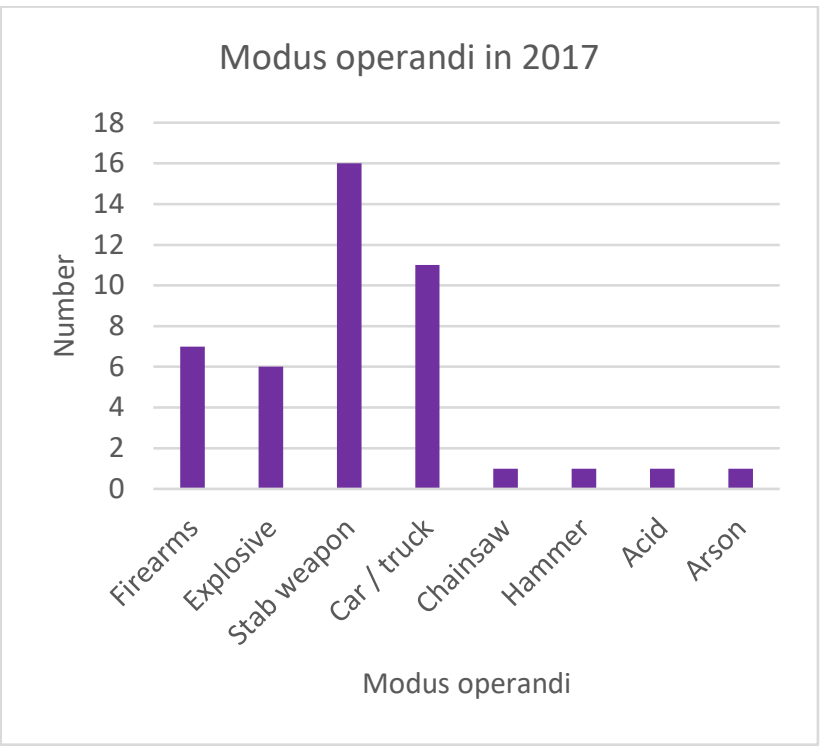

Fig. 5. Modus operandi in 2017 [8]

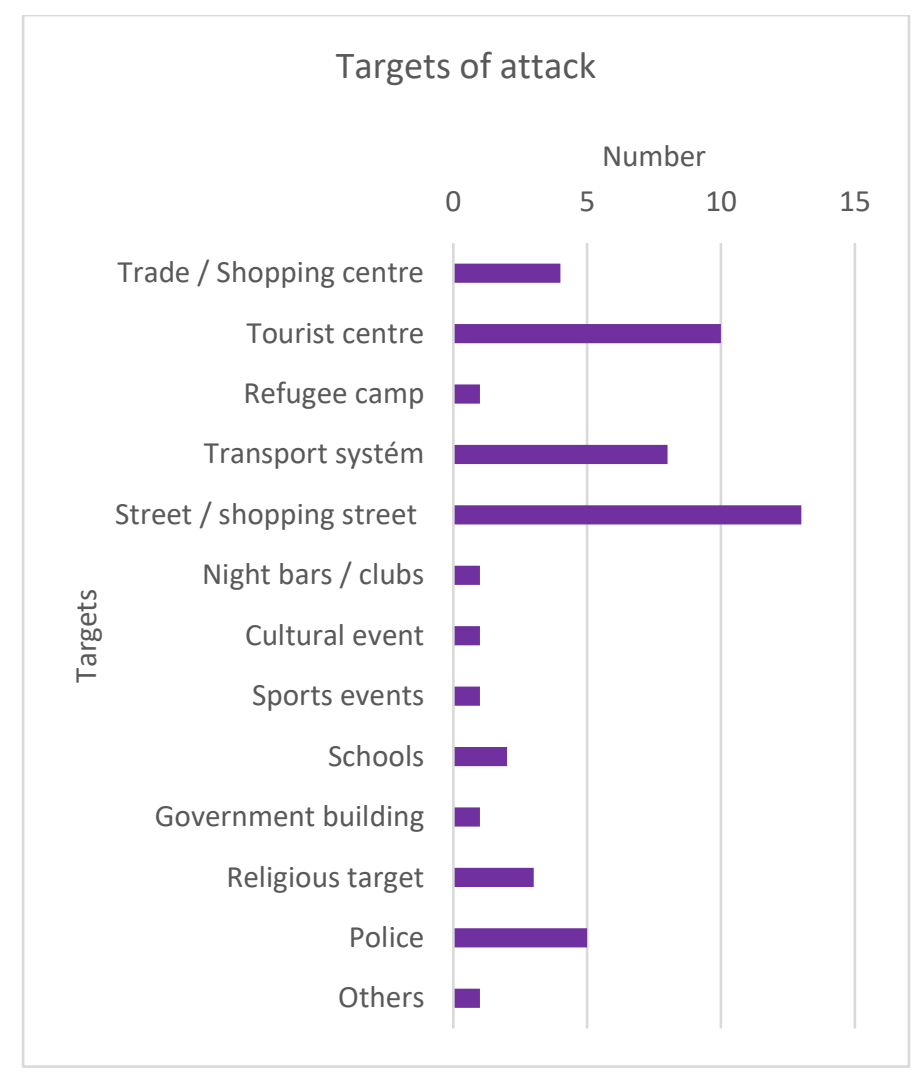

Fig. 6. Targets of attacks [8]

\section{Soft targets}

The Soft targets have been a hot topic in the last years. The year of 2017 was very tough for Europe because terrorist attacks were very often [5,8]. What did these attacks have in common? The targets were a shopping center, street, nightclubs, schools, etc. The security experts use the name for these objects and areas - the Soft targets. Ob. Cit.: "As "Soft Targets" can be referred to those objects, (open) spaces, or events characterized by the accumulation of a large number of people, the absence or low level of security measures against violent assaults and their omission among critical infrastructure and hard target objects." [7] 
The Soft targets include objects like airports, schools, shopping malls, religious sites, nightclubs and bars, tourist center, etc. [7] For the Soft targets, we distinguish three basic parameters - high concentration of people, low or no security against violent attacks and attraction for the attacker. The first two parameters can be read from the definition at the beginning of the section. Attractiveness is, however, a parameter that is related to choosing of the soft target as the target of the terrorist attack. An important point is the security against a violent attack. The object can be relatively wellsecured and still not protected against violent attack. For example - a shopping center. This is highly secured, but primarily against property crime (theft). CCTV systems, security gates, and security guards are everywhere. For violent attacks, these measures have no effect. It is not just the terrorist attack in the broader context. A violent attack is also active shooter, mentally disturbed person or otherwise motivated attacker. At present, however, the issue of the Soft targets is mainly linked to Islamic terrorism. Therefore, this article is primarily focused on threatening of the Soft targets by Islamic terrorists.

\section{Methods}

There are many different methods. Some methods are simple and fast, and some methods are very complex because they are based on fuzzy logic or machine learning, artificial intelligence. For the purpose of this research, the primary requirement is time. Only methods which are possible to process in short time period were chosen. Also, these methods are very spread and well-known:

- Scoring method

- Fuller's method (pairwise comparison)

- Saaty's method (quantitative pairwise comparison)

\subsection{Scoring Method}

This method is very often used in sports where performance cannot be measured by the exact way (evaluation in figure skating, gymnastics, etc.). The knowledge or experience is the main requirement for the evaluator. The expression of importance is done by assigns value to each criterion. The ${ }^{b_{i}}$ value is selected from the predefined interval (e.g. $b_{i} \in<0,100>$ ). A higher criterion value expresses greater importance. In addition, some criteria may have the same value. Same importance is not excluded. This simple method is from the category of quantitative methods, and it is very dependent on evaluator because it is a very subjective method. Even if evaluator has enough knowledge about the problem and has enough experiences, he still needs proper skills in prioritization to avoid conflict between his opinion and objective evaluation [11],[12],[13]. Normalization of assigned value is recommended to find weights (criteria strength) more accurate. The normalization process is straightforward. The assigned value for each criterion is divided by the sum of all criteria (1).

$$
v_{i}=\frac{b_{i}}{\sum_{i=1}^{k} b_{i}}
$$

\subsection{Fuller's Method}

This method has various names. One of these names is Fuller's triangle, but this method is used every day by everyone. This method is a pairwise comparison (as shown in Table 1). There are a lot of modifications and variations thanks to widespread of this method. However, the main principle is same. Comparing criterion with each other (a typical example is match table in sport). More important criterion than the second one receives a preferential point. In the most straightforward modification of this method, the number of preferences is found out with respect to all other criteria [14], [16]. It is good when all comparisons and relations are rewritten into the table (as shown in Table 1).

\begin{tabular}{|l|l|l|l|l|l|}
\hline Criterion & $K_{1}$ & $K_{2}$ & $K_{3}$ & $\ldots$ & $K_{n}$ \\
\hline$K_{1}$ & & 1 & 0 & $\ldots$ & 1 \\
\hline$K_{2}$ & & & 0 & $\ldots$ & 0 \\
\hline$K_{3}$ & & & & $\ldots$ & 1 \\
\hline$\ldots$ & & & & $\ldots$ & $\ldots$ \\
\hline$K_{n-1}$ & & & & & 0 \\
\hline$K_{n}$ & & & & & \\
\hline
\end{tabular}

Table 1. Weights determination via pairwise comparison - Fuller's method 
The last operation is again normalization which should be done by following formula (2) [14]:

$$
v_{i}=\frac{f_{i}}{m(m-1) / 2}
$$

$f_{i}$ : number of preferences of $i^{\text {th }}$ criterion

$m$ : number of criteria

$m(m-1) / 2$ : number of comparisons

However, what will happen if any criterion obtains zero preferences? Firstly, the probability is very low. The reason for this is simple; every time there appears at least one criterion which is a little bit better, and mainly, human decisions are inconsistent. This means that some of our claims should be in conflict. However, it may happen, that the weight of the criterion will be zero. This is the most significant disadvantage $[14,15]$. But there are few modifications that may help to avoid it. One of these modifications respects same significant criteria that may appear. Same importance is expressed by typing the number 0.5 into the cell [14].

\subsection{Saaty's Method}

This method is very similar to Fuller's Method. The only difference is in preferential points. Saaty formulated a scale of relative importance which affects the number of assigned preferential points. Comparison with an expression of relative importance creates a triangle matrix. The ${ }^{s_{i j}}$ vector defines a matrix, and its elements are interpreted as an estimation of the division of weights ( ${ }^{v_{i}}$ and $v_{j}$ ) for $i^{\text {th }}$ criterion and $j^{\text {th }}$ criterion [11], [13], [15].

$$
s_{i j} \approx \frac{v_{i}}{v_{j}}, \text { for } i, j=1,2, \ldots, m
$$

Weights should be approximated from a condition that S matrix $\left({ }^{s_{i j}}\right)$ differ only minimally from $V$ matrix (matrix contained from weights $-v_{i j}$ ). A special vector of $\mathrm{S}$ matrix, which is assigned to the highest number, is used for approximation of weights. The Saaty's scale of relative importance is used for defining $s_{i j}$ (described in more details in Table 2) [11], [13], [15].

$$
D=\sum_{i=1}^{m} \sum_{j=1}^{m}\left[s_{i j}-\left(\frac{v_{i}}{v_{j}}\right)^{2}\right] \rightarrow \min , \sum_{i=1}^{m} v_{1}=1
$$

This method is more comprehensive than simple pairwise comparison because it extends it. The first phase has similar steps as a pairwise comparison (Fuller's method). The main difference comes in the next phase that determines a size of preference with using the scale of relative importance [11], [14].

\begin{tabular}{|l|l|}
\hline Intensity & Definition \\
\hline 1 & Equally important \\
\hline 3 & Slightly more important \\
\hline 5 & More important \\
\hline 7 & Strongly important \\
\hline 9 & Absolutely more important \\
\hline $2,4,6,8$ & Intermediate values \\
\hline
\end{tabular}

Table 2. Saaty's scale of relative importance [14]

Three above mentioned methods were compared from the perspective of time and objectivity. Saaty's method provides the highest objectivity, but the fastest is the simple pairwise comparison. However, Saaty's method does not take more time. The difference is in seconds (comparison of 10 criteria). Final ranking for all three methods is shown in the following table (Table 3) [16]. 


\begin{tabular}{|l|l|l|}
\hline Method & Speed & Results \\
\hline Scoring & Average & 3 \\
\hline Pairwise comparison & Fast & 2 \\
\hline Saaty's method & Average - Fast & 1 \\
\hline
\end{tabular}

Table 3. Results comparison of MCDM and MoSCoW [16]

\section{Methods of Identification}

Three basic parameters were chosen to identify the subject as the Soft target - concentration of people, security measures against violent attacks and attractiveness. The concentration of people was divided into ten categories according to the character of their occurrence and mobility. The categories were assigned values from 1 to 10 , where the number of 10 is the most endangered form of person concentration (Table 4).

\begin{tabular}{|l|l|}
\hline Intensity & Definition \\
\hline 1 & Small number of people in large open place - scattered individuals (no groups) \\
\hline 2 & Medium number of people in a closed space (inside) \\
\hline 3 & Medium number of people in an open space (outside) - groups of people \\
\hline 4 & Large number of moving people - inside \\
\hline 5 & Large number of people, combination of moving and standing - inside \\
\hline 6 & Large number of standing people - inside \\
\hline 7 & Large number of people, moving from inside to outside or vice versa \\
\hline 8 & Large number of moving people - outside \\
\hline 9 & Large number of people, combination of moving and standing - outside \\
\hline 10 & Large number of standing people - outside \\
\hline 10 & Large number of standing people - outside \\
\hline
\end{tabular}

Table 4. Criteria of people accumulation

We used the statistics about places of attacks (Fig. 7) for the definition of categories, which are in table 4.

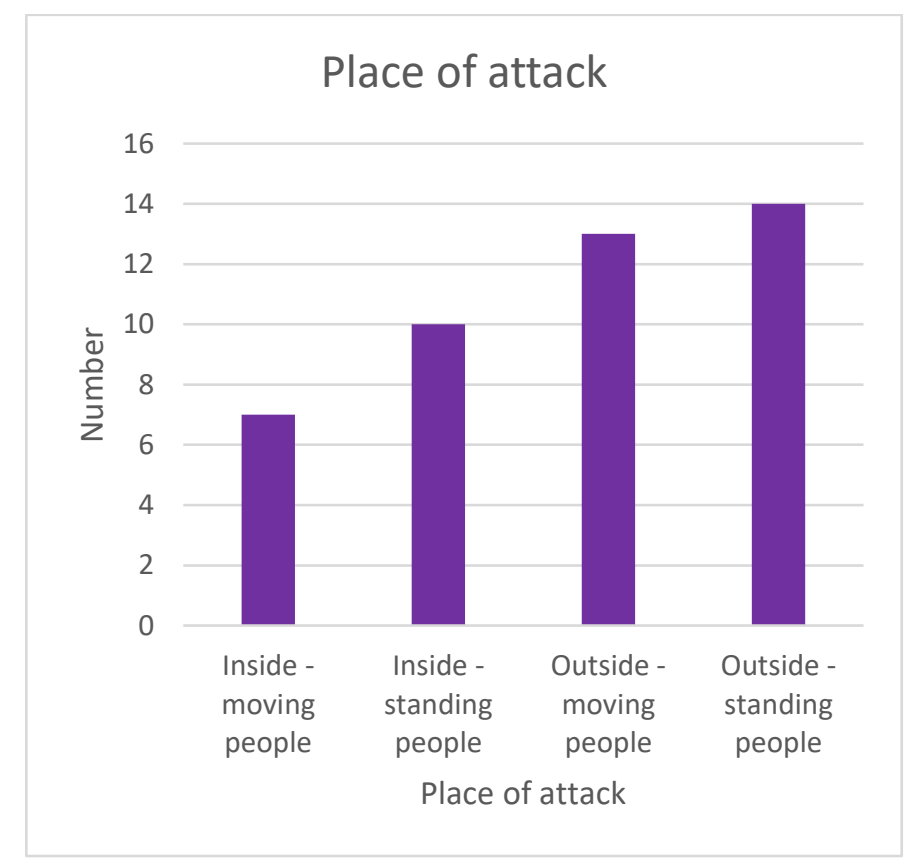

Fig. 7. Places of attacks [8]

The security measures against violent attacks were also rated from 1 to 10 , where the number of 10 means no security measures and number of 1 means that the security measures are as efficient as possible (Table 5). 


\begin{tabular}{|l|l|}
\hline Intensity & Definition \\
\hline 1 & Security guards - constantly - combination of static and mobile \\
\hline 2 & Security guards - constantly - mobile \\
\hline 3 & Security guards - constantly - static \\
\hline 4 & Security guards - in open hours of building - combination of static and mobile \\
\hline 5 & Security guards - in open hours of building - mobile \\
\hline 6 & Security guards - in open hours of building - static \\
\hline 7 & Security guards - sometimes in day - irregularly \\
\hline 8 & Security guards - sometimes in day - regularly \\
\hline 9 & No security guards - trained employees in security \\
\hline 10 & No security guards \\
\hline
\end{tabular}

Table 5. Criteria of security measures

A multi-criteria evaluation method was used for attractiveness. Based on attack statistics, seven categories of the Soft targets were created - a moderate Muslim community (1), a Jewish community (2), a Christian community (3), Western symbols (4), crowds (5), traffic hubs (6), armed forces (7). For these categories, the attractiveness rate for terrorists was determined with the help of the pairwise comparison (Table 6 and 7), described in section 4. The results were multiplied by 30 as a factor to reach the most attractive goal value at the upper limit of the scale from 1 to 10.

\begin{tabular}{|l|l|l|l|l|l|l|l|}
\hline & $\mathbf{1}$ & $\mathbf{2}$ & $\mathbf{3}$ & $\mathbf{4}$ & $\mathbf{5}$ & $\mathbf{6}$ & $\mathbf{7}$ \\
\hline $\mathbf{1}$ & 1 & 0,49 & 1,98 & 0,12 & 0,17 & 0,26 & 0,94 \\
\hline $\mathbf{2}$ & 5,44 & 1 & 5,75 & 0,20 & 1,90 & 2,17 & 3,59 \\
\hline $\mathbf{3}$ & 1,63 & 0,20 & 1 & 0,12 & 0,21 & 0,66 & 0,72 \\
\hline $\mathbf{4}$ & 8,75 & 5,75 & 8,38 & 1 & 5,25 & 6,63 & 7,00 \\
\hline $\mathbf{5}$ & 6,88 & 3,48 & 6,25 & 0,40 & 1 & 5,00 & 7,50 \\
\hline $\mathbf{6}$ & 4,88 & 2,16 & 2,81 & 0,16 & 0,32 & 1 & 4,38 \\
\hline $\mathbf{7}$ & 2,60 & 1,03 & 2,19 & 0,18 & 0,23 & 0,34 & 1 \\
\hline
\end{tabular}

Table 6. Pairwise comparison

\begin{tabular}{|l|l|l|}
\hline Categories & Results & Multiplied by 30 \\
\hline Western symbols (4) & 0,3391 & 10,1718 \\
\hline Crowds (5) & 0,2419 & 7,25752 \\
\hline Jewish community (2) & 0,1590 & 4,7707 \\
\hline Traffic hubs (6) & 0,1246 & 3,7374 \\
\hline Armed forces (7) & 0,0601 & 1,8024 \\
\hline Moderate Muslim community (1) & 0,0393 & 1,1802 \\
\hline Christian community (3) & 0,0360 & 1,0800 \\
\hline
\end{tabular}

Table 7. Results of pairwise comparison

The values of these three parameters were counted, and the results ranked.

Based on analysis of the terrorist attacks in Europe in the year of 2017, the boundary for naming the object as the Soft target was set at a number of 14 . This value was derived from the combination of values from individual parameters (attractiveness, concentration, security measures). This limit is used to define what the object or the event is the Soft targets. Values above number 14 show that the object is the Soft targets. The higher the value, the more important the object is, and there is a higher probability that the attacker chooses this object for the attack.

\section{Future studies}

This methodology for the Soft target identification has great potential in many security areas. In the framework of our future research, we would like to expand this study on the methodology of the vulnerability of the Soft targets according to statistical values and the elaboration of categorization based on the degree of threat. 
Depending on the categorization, we want to suggest appropriate and effective security measures. One of the measures, we see the behavioral analysis and profiling like the effective measures. We would like to implement profiling in our methodology. The profiling is a methodology that used security specialists for detection of characteristic marks and for communication with the suspect person. The goal is a revelation of possible criminal and terrorist intentions. This methodology is currently used mainly at airports, as well as important buildings such as department stores, some hotels, large social events, etc.

\section{Conclusion}

The terrorism in Europe is currently a topical issue. Due to the dynamic development of terrorist attacks in this area, the science and academic world is lagging behind. Security experts solve specific security problems, but they lack the methodological basis.

No comprehensive method of the identification of the Soft targets or their categorization has been developed yet. Our research has the ambition to fill these gaps. Our methodology could filter what the Soft target is and how much it is endangered. Based on this methodology, it is possible to prioritize objects.

Further development of our research will extend this study to a comprehensive categorization of the Soft targets based on threat. We have a goal to bring particular and effective security measures that will apply to individual categories. We will focus on the implementation of the behavioral analysis and profiling, which are currently one of the most effective preventive security measures.

\section{Acknowledgments}

This work was supported by the Ministry of Education, Youth and Sports of the Czech Republic within the National Sustainability Programme project No. LO1303 (MSMT-7778/2014) and also by the European Regional Development Fund under the project CEBIA-Tech No. CZ.1.05/2.1.00/03.0089 and also by the research project VI20172019073 "Identification and methods of protection of Czech soft targets against violent acts with elaboration of a warning system", supported by the Ministry of the Interior of the Czech Republic in the years 2017-2019 and also by the research project VI20172019054 "An analytical software module for the real-time resilience evaluation from point of the converged security ", supported by the Ministry of the Interior of the Czech Republic in the years 2017-2019.

\section{References}

[1] "Brussels explosions: What we know about airport and metro attacks", BBC, 2016 [online]. Available from: http://www.bbc.com/news/world-europe-35869985. [Accessed: 22- March- 2018].

[2] F. Klasna, "The largest terrorist attacks in Europe since 2000", Security magazin, 2016. [online]. Available from: http://www.securitymagazin.cz/zpravy/nejvetsi-teroristicke-utoky-v-evrope-od-roku-2000-1404051680.html. [Accessed: 11- Nov- 2016].

[3] "London Bridge attack: Timeline of British terror attacks", BBC, 2017 [online]. Available from: http://www.bbc.com/news/uk-40013040. [Accessed: 22- March- 2018].

[4] "Suspect fatally shot in Brussels Central Station terror attack", CNN, 2017 [online]. Available from: https://edition.cnn.com/2017/06/20/europe/brussels-train-station-incident/index.html. [Accessed: 22- March2018].

[5] "Timeline of recent terror attacks against the West", Fox news, 2017 [online]. Available from: http://www.foxnews.com/world/2017/11/01/timeline-recent-terror-attacks-against-west.html. [Accessed: 22March- 2018].

[6] "At least 22 killed, 59 injured in suicide attack at Manchester Arena", The Guardian, 2017 [online]. Available from: https://www.theguardian.com/uk-news/2017/may/22/manchester-arena-police-explosion-ariana-grande-concertengland. [Accessed: 22- March- 2018].

[7] Z. Kalvach, Definition of Soft Targets. Prague, 2017.

[8] T. Sternova, "Vývoj teroristických útoků v období 2014 - 2017. Rozbor vybraných útoků v roce 2017" (Development of terrorist attacks in 2014-2017. Analysis of selected attacks in 2017.). The Conference of Security Technologies, Systems and Management. Zlín, 2017.

[9] "ISIS Claims Responsibility for London Attack as Police Arrests 7", Bella nainja, 2017 [online]. Available from: https://www.bellanaija.com/2017/03/isis-claims-responsibility-for-london-attack-as-police-arrests-7/. [Accessed: 22- March- 2018].

[10] "Man arrested over Stockholm terror attack that killed four", Metro, 2017 [online]. Available from: http://metro.co.uk/2017/04/07/man-arrested-over-stockholm-terror-attack-that-killed-five-6561240/. [Accessed: 22- March- 2018].

[11] L. Kralik, R. Jasek, and R. Senkerik, "Multi-criterial evaluation-general overview," in 2016 International Conference of Numerical Analysis \& Applied Mathematics, Ialyso, 2016, pp. 445-449. 
[12] J. Fotr and L. Svecova, Managerial decisions: processes, methods and tools, Prague: Ekopress, 2010.

[13] J. Krupka, M. Kasparova, and R. Machova. Decision Processes, Pardubice: University of Pardubice, 2012.

[14] L. Kralik, R. Senkerik, and R. Jasek, "Comparison of MCDM methods with users' evaluation," in Sistemas y Tecnologías de Información: 11th Iberian Conference on Information Systems and Technologies (CISTI 2016), Gran Canaria, 2016, pp. 491-495.

[15] M. Cerny and D. Gluckaufova, Multicriterial evaluation in practice, Praha: Statni nakladatelstvi technicke literatury, 1982.

[16] L. Kralik, R. Jasek, R. Senkerik, P. Zacek and P. Holbikova, "Prioritisation by MoSCoW and Multicriterial Decision Making Methods.” 2017 IEEE International Conference on Logistics, Informatics and Service Sciences (LISS'2017) [online]. 2017, 53-57. ISBN 978-1-5386-1048-0.

[17] D. Lapkova, Z. Malanik and M. Adámek. "Use of the high-speed camera in self-defence". In Annals of DAAAM for 2011 \& Proceedings of the 22nd International DAAAM Symposium "Intelligent Manufacturing \& Automation: Power of Knowledge and Creativity". Vienna : DAAAM International Vienna, 2011, s. 1531-1532. ISSN 17269679. ISBN 978-3-901509-83-4. 